\title{
Efeitos da falha por ovalização de mancais hidrodinâmicos no lócus de eixos rotativos.
}

\author{
Matheus Victor Inacio*, Katia Lucchesi Cavalca Dedini (orientadora), Gregory Bregion Daniel (colaborador).
}

\section{Resumo}

Mancais hidrodinâmicos são um dos componentes mais importantes em máquinas rotativas, devido a sua grande influência no comportamento dinâmico do rotor e por estar sujeitos a diferentes tipos de falhas, tal como a ovalização que ocorre devido a deformação plástica no perfil do mancal. Assim, torna-se imprescindível avaliar como a ovalização influencia o comportamento do mancal, a fim de caracterizar as respostas do sistema quando operando em condições normais e de falhas, através da análise das respostas do lócus do eixo para diferentes níveis de ovalização do mancal.

\section{Palavras-chave:}

IMancal hidrodinâmico, Ovalização, Lócus do eixo.

\section{Introdução}

A fim de investigar os efeitos de falha por ovalização em mancais hidrodinâmicos, a equação clássica de lubrificação proposta por Reynolds[1] foi resolvida numericamente para a condição de carregamento estático através do método de volumes finitos. A espessura de filme de óleo usado neste trabalho é baseada no modelo de Silveira[2], que considera o perfil do mancal ovalizado através da magnitude $(K)$ e ângulo da deformação $(\kappa)$.

A partir dessa abordagem, é possível obter o campo de pressão de um mancal ovalizado, e consequentemente, as forças hidrodinâmicas que são exercidas sobre ele através de uma integração do campo de pressão sobre o domínio do mancal. Assim, para um dado carregamento no eixo, pode-se então determinar as posições de equilíbrio do eixo (excentricidade) em cada rotação, garantindo assim que a soma vetorial entre as forças hidrodinâmicas e a carga do eixo seja zero (balanço de forças). Dessa forma, obtém-se então a curva do lócus do eixo no mancal hidrodinâmico.

\section{Resultados e Discussão}

Para avaliar a influência da ovalização sobre o comportamento estático do rotor, foram simulados o lócus do eixo considerando diferentes níveis de ovalização no mancal. Nessa análise foi usado um modelo de mancal com $30 \mathrm{~mm}$ de diâmetro, $30 \mathrm{~mm}$ de comprimento, $90 \mu m$ de folga radial e um óleo lubrificante ISOVG32 com viscosidade de 0,051 Pa.s. A carga do eixo utilizada foi de $100 \mathrm{~N}$ e variou a rotação do eixo de $2 \mathrm{hz}$ a $50 \mathrm{hz}$. Além disso, uma malha de $50 \times 50$ volumes foi considerada para discretizar o domínio do mancal.

De forma a avaliar a influência de cada parâmetro da ovalização $(K$ e $\alpha)$, inicialmente fixou o ângulo de deformação $\alpha$ em 0 e variou a magnitude da deformação $K$, de 0 a $12 \%$ da folga radial $\mathrm{Cr}$. Após isso, fixou a magnitude $K$ em $12 \%$ da folga radial e variou o ângulo da deformação $\alpha$ de $0^{\circ}$ a $150^{\circ}$. Em cada um desses casos foram plotados o lócus do eixo no mancal.

Observando a Figura 1 foi possível verificar que, o lócus do eixo tende a se deslocar para baixo conforme aumenta a magnitude da deformação, indicando que o mancal perde capacidade de carga. Já na Figura 2, percebe-se que a variação do ângulo de deformação de 0 a $90^{\circ}$ faz com que a curvatura do lócus desloque para a direita. Esse comportamento indica que a variação no lócus tende a acompanhar a posição angular da deformação.

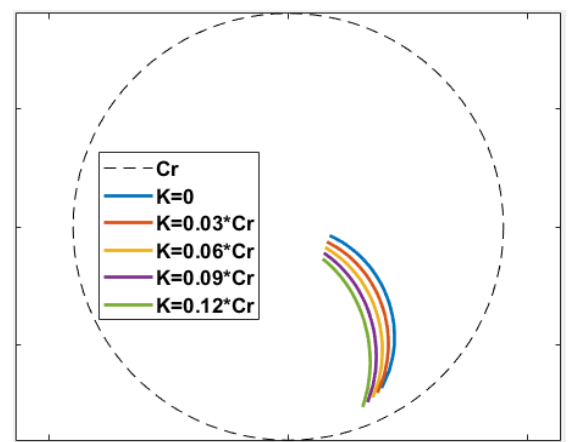

Figura 1. Lócus do eixo com $K$ variando e $\alpha$ constante

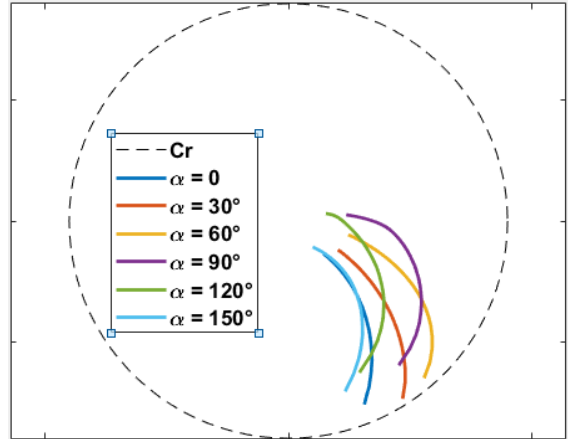

Figura 2. Curvas Lócus com $K$ constante e $\alpha$ variando

\section{Conclusões}

Com base nos resultados obtidos foi possível verificar que a ovalização pode deslocar o lócus para baixo, indicando uma perda de sustentação do mancal, enquanto o ângulo de deformação tende a deslocar as curvas no interior do mancal. Diante disso, conclui-se que a ovalização tem grande influência sobre o lócus do eixo, que representa uma importante resposta para caracterizar o comportamento do mancal hidrodinâmico.

\section{Agradecimentos}

Agradecimentos à Universidade Estadual de Campinas e a FAPESP pelo apoio financeiro (2019/11070-6).

[1]Reynolds, 0. "On the theory of lubrication and its application to $\mathrm{Mr}$. Beauchamp Tower's experiments, including an experimental determination of the viscosity of olive oil”, Proc. Royal Soc. Lond., 1886, 40, pp. 191-203.

[2]Silveira, A.R.G.; Daniel, G.B. "Influence of bearing ovalization in the dynamic of a planar slider-crank mechanism". Applied Mathematical Modelling, 2019, 66, pp 175-194. 